\title{
INCOMPLETE RUPTURE OF THE ASCENDING AORTA WITH SECONDARY ANEURYSM
}

\author{
BY \\ JOHN WEDGWOOD \\ From Addenbrooke's Hospital, Cambridge
}

Case reports of incomplete rupture of the aorta with aneurysm formation due to stretching of the weakened aortic wall, without dissection, are rare. The following case is of interest because of its rarity, its possible traumatic ætiology, and the patient's long survival.

\section{Case Report}

A previously healthy farm worker, aged 27 years, was admitted to Addenbrooke's Hospital, as an emergency, under Dr. Leslie Cole, on March 16, 1949. He complained of severe pain in the chest.

The evening before admission, he had been walking home from a football match, where he had been an enthusiastic spectator, when he was suddenly struck by a severe pain in the back and chest. The onset was "as if an arrow had hit him between the shoulder blades." The pain was felt all over the chest. It was maximal under the sternum and radiated into the neck, back, epigastrium and later the right shoulder. The pain soon became agonizing; it was "tearing" in character and made worse by breathing. He felt very ill and sweated profusely. He managed to walk to his house about 40 yards away. The pain lasted all night, preventing sleep, and was associated with retching and vomiting. He was admitted to his local hospital and later transferred with a provisional diagnosis of ruptured œsophagus.

He had been a fit and active man before this illness. He worked as a farm labourer and was also a smallholder. He played football regularly at weekends. Three weeks before admission he had been thrown from his motor cycle and had fractured his left radius. There was no known chest injury or chest pain at the time. There was no past history of rheumatic fever and no other relevant past history.

The family history, most of which was supplied by the patient's general practitioner, Dr. J. K. Paterson, is of interest, although unfortunately incomplete. The patient's father died of carcinoma of the lung, aged 59; he was a stocky well-built man like the rest of his family. The patient's mother was apparently well; she had five sisters and two brothers; all with one exception were tall and thin. One of the brothers, killed in the 1918 war, aged 20, had been exceptionally tall, and was noted for his long delicate fingers. The patient had one brother, aged 34, who was said to have a bad heart.

On admission, about 24 hours after the onset, he was feeling better and had only a dull, aching pain in the centre of the chest and in the right shoulder tip, made worse by deep inspiration.

He appeared a healthy, muscular man about $6 \mathrm{ft}$. tall. He was afebrile although he ran a lowgrade fever during the three days after admission. There was no evidence of arachnodactyly. His left forearm was in plaster. No abnormality was detected in the peripheral pulses and the femoral pulses were present and equal.

The most prominent physical sign was a loud aortic diastolic murmur heard best at the left sternal edge. The pulse was regular and not collapsing. The blood pressure on admission was raised (170/135) but later readings were lower and equal in both arms (140/70). There were no 
signs of heart failure. There was no sternal pulsation or evidence of superior vena caval obstruction. There were signs of a raised diaphragm at the right lung base. There was some guarding and tenderness to palpation in the epigastrium. No other relevant abnormality was found. The urine contained no albumen or other abnormality on routine tests.

Chest X-ray and cardioscopy were performed by Dr. Brian Donnelly before the patient was taken to the ward. The superior mediastinum showed generalized broadening and its structures were completely obscured. The aortic arch was completely obscured together with the aortic window and aortic triangle in the left oblique position. The left ventricle was enlarged. The right diaphragm was raised and its movements limited. A barium swallow showed a normal œsophagus.

An electrocardiogram showed patterns of acute pericarditis (Fig. 1).

A full blood count showed: leucocytes, 12,400 per c.mm. with 76 per cent neutrophils ( 9424 per c.mm.); hæmoglobin: $16 \cdot 3$ g. per $100 \mathrm{ml}$. The blood W.R. and Kahn were negative.

A provisional diagnosis of dissecting aneurysm of the ascending aorta and aortic regurgitation was made. The patient was treated with strict bed rest and sedation. The day after admission he had no pain and felt reasonably well.

Three weeks later he had a further attack of chest pain lasting four hours and associated with fever of $100^{\circ} \mathrm{F}$. Clinical examination showed the presence of a loud pericardial friction rub. The electrocardiogram again showed evidence of acute pericarditis (Fig. 1).

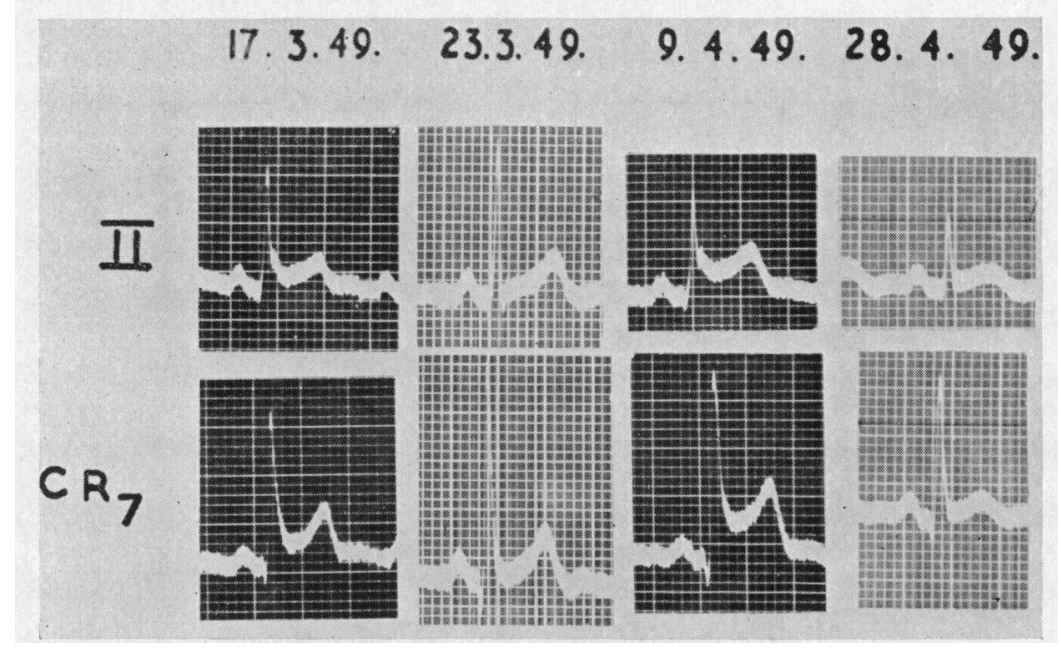

FIG. 1.-Serial cardiograms, showing recurrent patterns of acute pericarditis.

A third, but less severe attack of pain, also with evidence of acute pericarditis, occurred three weeks later.

The subsequent progress in hospital was uneventful. He was gradually allowed up and discharged, twelve weeks after admission. Examination before discharge showed the presence of aortic regurgitation (B.P. 140/90). Cardioscopy showed the appearances of an aneurysm of the ascending aorta with enlargement of the left ventricle.

He started light clerical work six months later. During the next two years he kept fairly well except for occasional sharp pains in the right side of his neck and a short attack of paroxysmal auricular fibrillation for which he was again admitted to hospital in March, 1951.

In 1952, he decided against advice, to start heavier work. He began work on his smallholding and also got married. In April, he developed persistent auricular fibrillation. There followed a gradual deterioration in his condition. He became progressively more short of breath 
and the signs of aortic regurgitation increased. In May he had a further attack of chest pain, lasting a few minutes, which radiated down his left arm and woke him from sleep. Chest X-ray in July showed increased enlargement of the left ventricle and an increase in prominence of the aneurysm of his ascending aorta (Fig. 2).

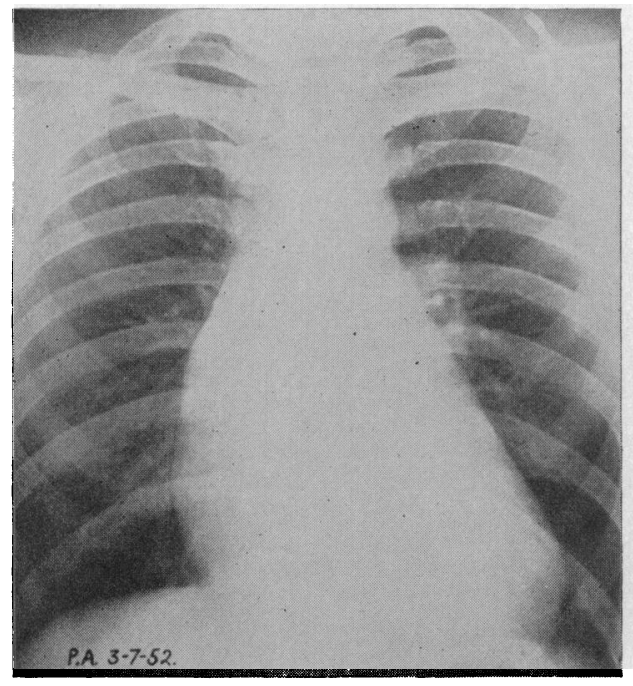

A

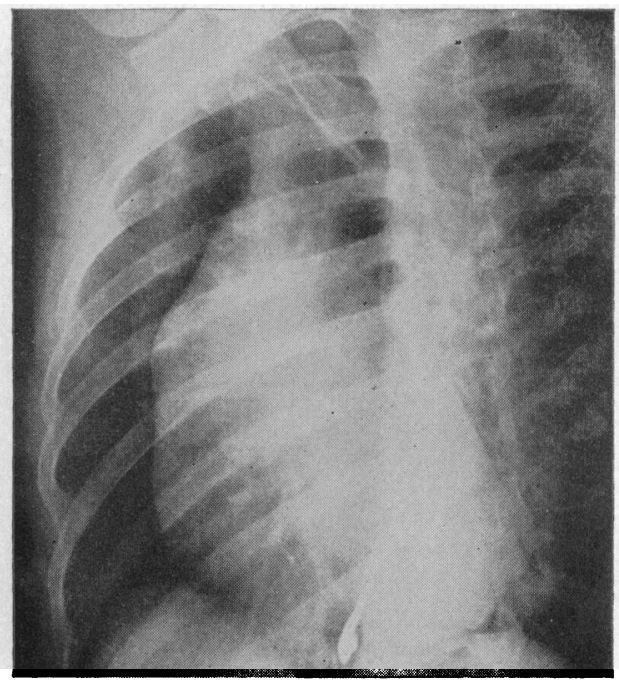

B

Fig. 2.-Chest X-rays, showing aneurysm of ascending aorta. (A) Postero-anterior view.

(B) Left oblique view.

On September 30, 1952, about three years after his first symptoms, he developed another attack of chest pain which lasted all night. He was admitted to hospital on the following day, when he was found to be in congestive heart failure with rapid auricular fibrillation. There was no improvement with routine treatment and he died following multiple pulmonary embolisms one week later.

\section{Post-mortem Examination.}

The following are extracts from the report by Dr. A. M. Barrett.

Cardiovascular System. A ragged laceration of the greater part of the thickness of the ascending aorta completely encircles the vessel just above the aortic valve. The two margins of the laceration have been separated by a distance of about $5 \mathrm{~cm}$., and in this gap the aortic wall consists only of a thin layer of fibrous tissue, except that there are a few raised islands formed by detached fragments of the original aortic wall. The smoothness of the inner surface of the fibrous tissue in the gap, and the rounding off of the margins of the laceration prove that the laceration is old.

There is an intrapericardial aneurysmal dilatation of the damaged ascending aorta (Fig. 3): the dilatation involves the aortic ring $(11 \mathrm{~cm}$. circumference), is maximal at about the middle of the gap $(22 \mathrm{~cm}$. circumference), and finishes at the origin of the carotid arteries.

The descending thoracic and abdominal portions of the aorta are normal in size, appearance, and elasticity (descending thoracic aorta immediately beyond the left subclavian artery, $5.3 \mathrm{~cm}$. circumference; abdominal aorta, $4.3 \mathrm{~cm}$. circumference): in the abdominal aorta, however, there are buttons of atheroma.

The aneurysm contains post-mortem blood clot only, except that there is a plug of ante-mortem thrombus peeping through an apparently recent secondary laceration, having abrupt margins, situated just above the right commissure of the anterior cusp of the aortic valve; and another similar plug of ante-mortem thrombus peeping through a smaller vertical recent laceration in one of the islands of detached aortic wall on the posterior aspect of the aneurysm. 
The aortic valve is congenitally bicuspid and has been rendered incompetent by dilatation of the ring, with separation $(0.5 \mathrm{~cm}$.) of the adjacent cusps on the left, and stretching of the cusps.

The mitral, tricuspid, and pulmonary valves are normal. Nowhere have the lacerations extended for any considerable distance within the aortic wall: the aneurysm is not a dissecting aneurysm. Only a thin layer of fibrous tissue, however, separates the blood in the lumen of the aorta from the pericardial cavity, and it is very probable that there have been leakages of blood into the pericardium; for the pericardial cavity has been obliterated by fibrous adhesions which are not very tough, and in some places are stained greenish-brown as if by altered blood.

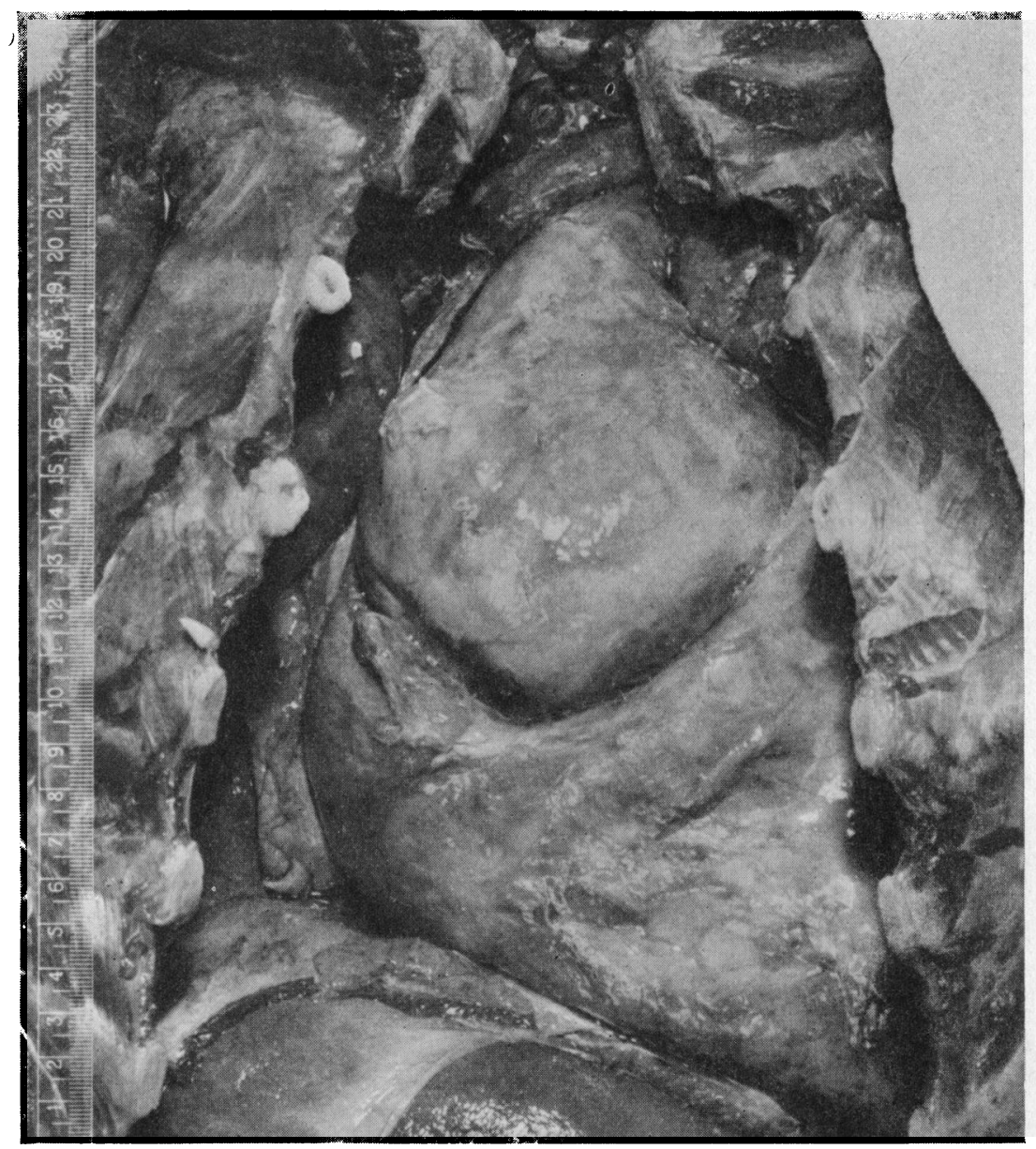

FIG. 3.-Photograph of the heart at necropsy, showing aneurysm of the ascending aorta.

Both left and right ventricles are greatly hypertrophied, and the endocardial surface of the left side of the interventricular septum shows the thrush's breast mottling of fatty degeneration.

A plug of ante-mortem thrombus fills the left auricular appendage. The coronary arteries and their orifices are well developed and healthy, showing only a slight degree of atheroma.

Histology. A longitudinal section of the ascending aorta taken through the upper border of the tear shows that the media of the aorta has been torn completely across, and in the gap between the separated borders of the tear the wall consists of thickened adventitial fibrous tissue, with an inner newly formed layer of connective tissue, in which there is much mucoid material with some delicate elastic fibrils. There 
is no evidence of dissection into the healthy part of the aortic wall. A section of the aorta at the level of the diaphragm shows a considerable amount of interfibrillary mucoid material-more than I should have expected in a healthy patient of this age-but there is no true medionecrosis.

The lungs show congestive changes and two recent hæmorrhagic infarcts. The liver, spleen, and kidneys show chronic passive venous congestion.

\section{Discussion}

There was no dissection of the wall of the aorta in this case. The aneurysm appeared to be due to an incomplete and partially healed rupture of the ascending aorta with subsequent stretching of the weakened aortic wall. Pathologically this can be considered a " secondary true aneurysm " (Kaufmann, 1929). Reports of this condition are much less common than those of dissecting aneurysm. Search of the necropsy records at this hospital, over a nine-year period (1946-1955) revealed no similar cases, whereas there were 58 other cases of aortic aneurysm including 26 cases of dissecting aneurysm and 5 cases of syphilitic aneurysm.

The post-mortem appearances of incomplete rupture of the aorta with secondary aneurysm were discussed by Asahi (1905). Cases with both clinical and post-mortem records have been described by Heller (1904), Gravier (1924), Laves (1925), Lundberg (1930), Eskelund (1941), and Wenger (1943). In the six cases described by these authors and in the present case the site of rupture and secondary aneurysm formation, the occurrence of aortic regurgitation and death in congestive heart failure, were common features. Chest pain was rare and noted in Heller's case only. An additional finding in the present case was the clinical and electrocardiographic evidence of acute pericarditis. This appeared to be due to slow leakage of blood into the pericardium. Similar changes have been described in dissecting aneurysm (Levinson et al., 1950) but are uncommon. The pericardium which invests the ascending aorta may favour the development of secondary aneurysm in the cases described in all of which rupture occurred a short distance above the aortic valves.

Survival for three years with an incomplete rupture of the aorta of this severity is exceptional. It is hoped that it was related to the strict rest which was enforced from the beginning of the patient's illness. His rapid deterioration when he returned to heavy work, against advice, confirms the importance of restricting the activities of these patients. The importance of adequate rest emphasizes the necessity for early diagnosis.

Complete tears of the aorta following severe chest injuries are well known. Direct injury to the chest is, however, not a common cause of either dissecting aneurysm (Shennan, 1934) or incomplete rupture of the aorta. In the case described by Heller (1904) incomplete rupture of the aorta appeared closely related to sudden strain, when the patient, who had been carrying a heavy girder with three other men, was left to take the weight by himself. In the present case there was no definite chest injury but it is possible that the initial rupture of the aorta took place in the motor-cycle accident three weeks before the onset of symptoms. Rice and Wittstruck (1951) reported a case of delayed traumatic rupture of the aorta and dissecting aneurysm following a motor accident. The patient, a pregnant girl of 20 , struck the upper part of her chest against the seat in front of her but received a few external bruises only. Rupture of the aorta was attributed to rapid deceleration. This possible cause of rupture of the aorta in motor accidents has also been discussed by Tannenbaum and Ferguson (1948).

A healthy aorta is able to withstand exceptional pressures (Oppenheim, 1918) but in the present case there is reason to suppose that the aortic media was abnormal and more liable to rupture as a result of injury. The family history is also suggestive that this case may have been a " forme fruste" of Marfan's syndrome (Reynolds, 1950).

Aneurysm of the ascending aorta with aortic regurgitation is a common finding in Marfan's syndrome and incomplete tears of the aorta may also be found (Moses, 1951). The findings in the present case were in some respects similar except that the aneurysm appeared to have been caused by the tears in the aorta. The possibility that some degree of aortic dilatation and aortic incompetence had preceded the condition cannot be excluded. 


\section{Summary}

A case is described of incomplete rupture of the ascending aorta with secondary aneurysm formation in a man aged 27 years. The rupture was also associated with aortic regurgitation and acute pericarditis. Recurrent episodes suggesting further tears occurred and death took place three years later from congestive heart failure with auricular fibrillation.

The rupture may have been caused by trauma but there was also some evidence that the aorta was abnormal and that the case may have been a "forme fruste" of Marfan's syndrome.

The importance of early diagnosis and adequate rest in suspected cases of rupture of the aorta is emphasized.

I thank Dr. Leslie Cole for permission to publish this case and Dr. A. M. Barrett for permission to publish the necropsy report and for help in the preparation of this paper. I would also like to acknowledge my thanks to the late Dr. Brian Donnelly for the X-rays and radiological findings. I am grateful to Dr. J. K. Paterson for the information about the patient's family history.

\section{References}

Asahi, K. (1905). Z. Heilk., 26 (N.F. 6), 163.

Eskelund, V. (1941). Ugeskr. Lag., 103, 240.

Gravier, L. (1924). J. Méd. Lyon, 5, 563.

Heller, A. (1904). Disch. Arch. klin. Med., 79, 306.

Kaufmann, E. (1929). Pathology. (Trans. Reimann), London, p. 147.

Laves, W. (1925). Wien. klin. Wschr., 38, 804.

Levinson, D. C., Edmeades, D. T., and Griffith, G. C. (1950). Circulation, 1, 360.

Lundberg, A. (1930). Acta med. scand., 73, 19.

Moses, M. F. (1951). Brit. med. J., 2, 81.

Oppenheim, F. (1918). Münch. med. Wschr., 45, 1234.

Reynolds, G. (1950). Guy's Hosp. Rep., 99, 178.

Rice, W. G., and Wittstruck, K. P. (1951). J. Amer. med. Ass., 147, 915.

Shennan, T. (1934). Dissecting Aneurysms. M.R.C. Special Report Series, No. 193. H.M.S.O. London.

Tannenbaum, I., and Ferguson, J. A. (1948). Arch. Path., 45, 503.

Wenger, F. (1943). Arch. Path., 36, 253. 